\title{
Measuring the Impact of Third Place Attachment on the Adoption of a Place-Based Community Technology
}

\author{
Shelly D. Farnham, Joseph F. McCarthy, Yagnesh Patel, Sameer Ahuja, \\ Daniel Norman, William R. Hazlewood, Josh Lind \\ Strands Labs \\ 4143 University Way NE, Seattle WA 98105 USA \\ shelly@pathable.com
}

\begin{abstract}
CoCollage is a placed-based community technology that leverages the power of online social networking to facilitate awareness and face-to-face interactions in a third place. We adapted standardized measures of place attachment, social networks and psychological sense of community to provide a framework grounded in the social science literature for studying real world adoption of place-based community technologies. We found the standardized measures of place attachment and psychological sense of community meaningfully predicted likelihood of technology adoption and usage in a café. We discuss some lessons learned from our initial deployment of CoCollage in a real-world setting to support a nascent place-based community.
\end{abstract}

\section{Author Keywords}

Online social networks, social media, physical spaces, third places, proactive displays, ubiquitous computing, community, place-based community, place.

\section{ACM Classification Keywords}

H.5.3 [Information Interfaces and Presentation]: Group and Organization Interfaces - synchronous interaction, asynchronous interaction, web-based interaction.

\section{INTRODUCTION}

Cafés and coffeehouses are prototypical third places [6]: semi-public places away from home (first places) and work (second places) where people can gather to enjoy conversation and community with friends and strangers. These third places facilitate community development by providing their inhabitants with a vehicle for frequent serendipitous interactions, which increase the likelihood of developing interpersonal relationships [7].

CoCollage provides an architecture of participation [4], linking online profiles, media sharing and conversation tools with a large computer display that shows content from

Permission to make digital or hard copies of all or part of this work for personal or classroom use is granted without fee provided that copies are not made or distributed for profit or commercial advantage and that copies bear this notice and the full citation on the first page. To copy otherwise, or republish, to post on servers or to redistribute to lists, requires prior specific permission and/or a fee.

CHI 2009, April 4-9, 2009, Boston, MA, USA.

Copyright 2009 ACM 978-1-60558-246-7/08/04_..\$5.00 people's profiles when they use their loyalty cards in the café (see Figure 1). CoCollage serves both as a physical window into the community, increasing people's awareness of people currently in the café through the display, and a virtual window, facilitating awareness and asynchronous interactions among those not currently present.

We deployed CoCollage in a community-oriented, realworld café to a) develop a better understanding of the psycho-social factors that would impact adoption and use, b) get immediate feedback for iteratively improving design, and c) explore how best to measure place-based community development for future studies.

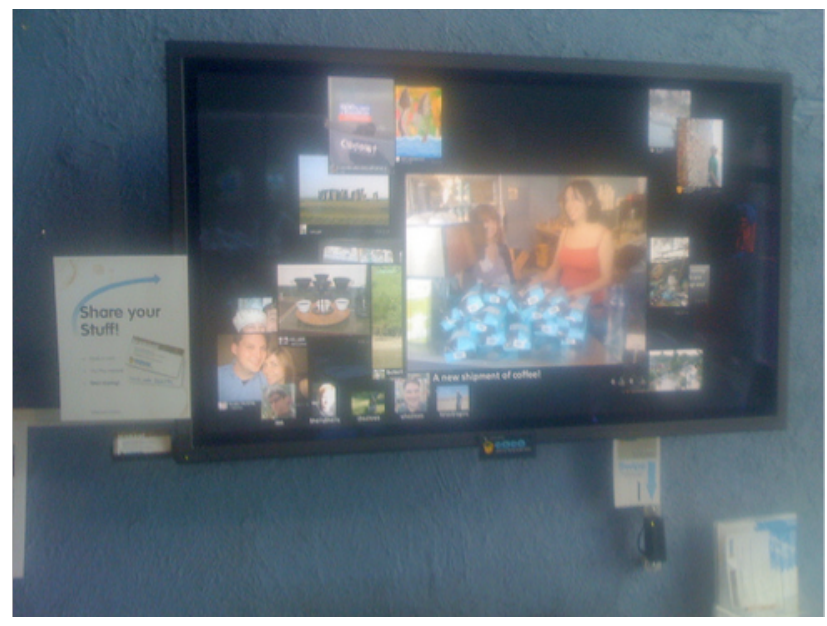

Figure 1. The CoCollage display shows a mix of images and quotes posted by community members.

This paper describes our exploration of the social space in which we deployed CoCollage and a methodology that is useful to learning more about the psycho-social factors that impact technology adoption and use in such places. Having established that this methodology is appropriate to understanding the adoption of a new technology, future work may focus on the impact on sense of community and loyalty to the third place.

\section{THE COCOLLAGE SYSTEM}

Online profile and media sharing tools allow users to create an account, describe themselves, and then upload media to share - much like photo sharing sites such as Flickr. CoCollage supports a few types of online 
conversations around the shared content, because conversation is key to community development. Our goal in designing the online component of CoCollage was that the online photo sharing and conversation tools would help third place relationships develop through both synchronous and asynchronous interactions (see Figure 2). Members may comment on others' profiles, vote or comment on others' content items, participate in a general "chatter" area, and send public messages directly to the CoCollage display. A visualization component shows a continuously updated collage of media items on a large screen in the café that draws from the pool of all café community members, but prioritizes people who are physically present. An algorithm selects content items to appear on the collage based on the freshness of the content, its popularity in the community, and the frequency with which the users who share content visit the café. Through presence detection - "checking in" by using their machine-readable loyalty cards or clicking on a link on the CoCollage web site while in the café - the collage prioritizes the content shared by people who are physically present in the café.

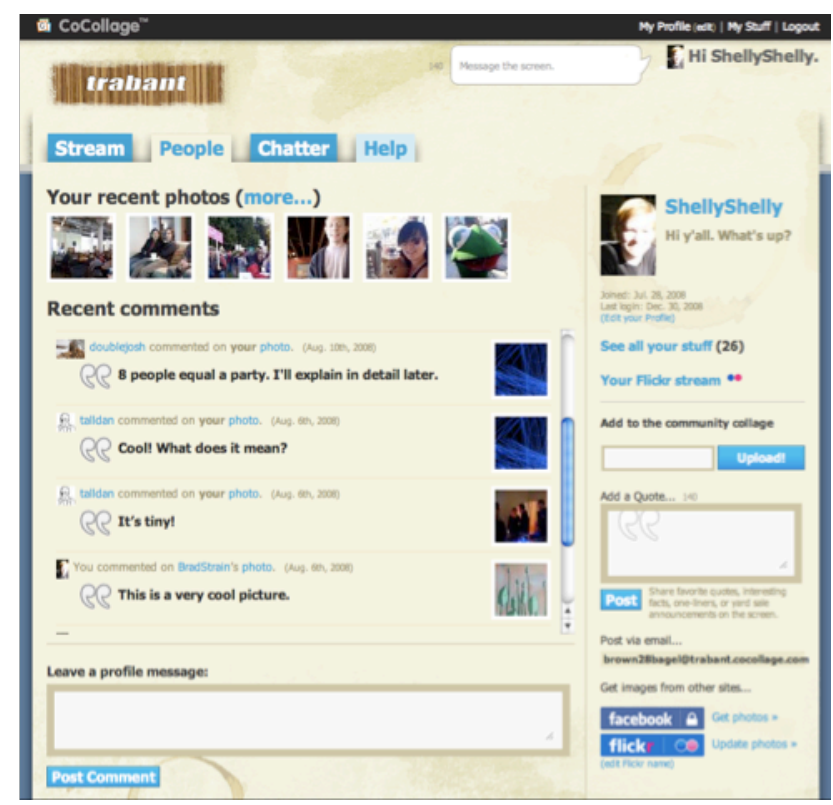

Figure 2. The CoCollage online profile has recent photos, comments, and tools for adding new content.

A number of other researchers have explored collaborative sharing around community displays. The Notification Collage [3] enabled a small workgroup to share media items on personal and semi-public computer displays; however, there was no notion of "presence" for the semipublic display and the community in which it was deployed was much more closely knit than the community in a café. The C3 Collage [5] incorporated a notion of presence, showing photos from users' Flickr accounts on a large touch-screen computer whenever their Bluetooth phones were detected nearby, but this, too, was deployed in a workplace with a stronger sense of community than a café.
The eyeCanvas plasma poster application [2] was deployed in a café, but use by patrons was constrained to finger doodles; while this work yielded interesting insights into interactions and effects, it did not delve into the existing desire for interactions among patrons and its impact on adoption and subsequent community development, which is the primary contribution of this work.

\section{EARLY DEPLOYMENT AND STUDY PROCEDURES}

\section{Research Goals}

During our early deployment, our primary research goals were to gain a better understanding of the existing café community that makes up our prospective user population. More specifically, these goals included evaluating a) the size and activity of the community, b) the level of their existing sense of community or attachment to the café, c) the extent to which they are interested in meeting people and developing community in and through the café, and d) whether those with a desire to meet others were more likely to contribute to the community collage. Given the challenge of measuring "community", our intention is also to identify potentially valuable instruments for assessing the impact of place-based community technologies.

\section{Measuring Sense of Community and Place Attachment} In developing measures of sense of community for a placebased community technology, we draw from the long history of community research that has been performed in the social sciences. Reviews of community research point to several standardized measures of social networks and psychological sense of community [9], some of which have already been adapted to virtual communities [1] and to third places [7]. Rosenbaum et al. [7] proposed a framework for understanding the relationship between the social support that is experienced in third places and customer attachment to those places. In their study of customers at a suburban diner in Chicago, they found that people with a lack of social support in some aspects of their lives were more likely to develop supportive relationships in a third place. These customers subsequently developed place attachment, that is, a bond between a person and a place.

We similarly expect that people will be more likely to adopt a community technology in a third place if they are looking to develop new friendships. They may also adopt the technology because they already have a sense of community and place attachment. They may wish to nurture existing relationships and express their sense of belonging by personalizing the physical space.

For our study we adapted the standard network-based inventory approach used by Rosenbaum et al. [7] to measure the size of place-based networks. We asked people to count the number of people they considered to be friends and acquaintances within the café. We also asked a number of questions to assess whether they were seeking new friendships. We adapted the psychological sense of community measure [9] to apply directly to sense of community within the café, which includes questions such 
as "My friendships and associations with others at [café] mean a lot." We then adapted questions from Rosenbaum's study [7] assessing the three dimensions of place attachment - functional dependency, commitment to continue using the café, and identification with self - with questions such as "Coming to [this cafe] is more important to me than going to other cafes".

\section{Café Deployment and Study Procedures}

CoCollage was initially made available to just the staff within our participating café for a week of in-situ testing and to gather a critical mass of initial content from an immediately enthusiastic subgroup of the café community. We then opened up the system to all members of the community. Accounts were restricted to customers who actually visited the café by requiring people to use invitation codes printed on cards that were placed in the café near the display. As of this writing, the system has been running continuously in the café for five weeks.

During the week we first opened the system to customers, we spent a number of hours over five days stationed at one of the tables in the café, recruiting people to complete a paper questionnaire about their existing social network, sense of community, and place attachment for the café. Participants received a $\$ 10$ café gift card in exchange for participation. We also offered people who independently created CoCollage accounts to participate in an online version of the questionnaire with the same compensation.

\section{RESULTS}

\section{The Participating Café}

We interviewed the proprietors and conducted several onsite observations at varying times and days of the week to better understand the social context of the café. The proprietors of the café are dedicated to developing a strong community among their customers, and have a positive attitude towards technology. Based on the number of weekly purchases, and the number of people in their loyalty program, they estimated about 400 "regulars" visited once or twice a week. These regulars constitute the most likely subgroup to become CoCollage users.

Our observations involved logging the times that people entered and exited the café, whether they sat down after purchasing a drink, and whom they talked to. We observed a total of 163 people over 7 hours, $61 \%$ male, 39\% female, an estimated average of 28 years of age. We found that at any given time there were about 17 people in the café. 23 new people came in each hour, staying an average of 25 minutes each. $64 \%$ sat down in the café after purchasing their drinks. Among the 62 people (38\%) who entered the café with friends, we observed nearly all of them chatting with their friends, $12 \%$ of them chatting with a barista, and only two who ever chatted with a person at another table.

These observations highlight why place-based synchronous chat applications do not tend to succeed in third places (e.g., Meetro and Trepia). There will generally not be enough people in the space to achieve critical mass for meaningful chat interactions. Tools for asynchronous awareness and interaction considerably increase the span of time during which a person may serendipitously become aware of or interact with others through the third place.

\section{Questionnaire Results}

69 people completed the questionnaire, 33 male, and 36 female, with an average age of 29. Of these, 24 respondents had also joined CoCollage. Most of the participants had completed at least some college (91\%) with $23 \%$ having a college degree or higher. 23\% categorized themselves as students, and $51 \%$ as having white collar/professional jobs.

$77 \%$ of respondents reported visiting the café two times a month or more, with $58 \%$ at least once a week and $38 \%$ a few times a week. 75\% reported staying and sitting in the café at least sometimes. The majority who stay and sit report sitting for $15-60$ minutes. Primary activities include chatting with friends $(65 \%)$, reading $(46 \%)$, and working on a laptop (39\%). These numbers are consistent with our observations and the owners' estimates.

We asked respondents to indicate their satisfaction with the café on a scale of 1 to 7 , where $1=$ "not at all" and $7=$ "extremely so". Respondents were generally satisfied with the ambience $(M=5.6)$, their social experiences in the café $(M=5.3)$, and believed that the café proprietors were interested in building a sense of community $(M=5.5)$. About $56 \%$ indicated at least some interest in connecting more with others in the café. We also found that most people were at least somewhat interested in seeking new friends generally $(M=4.5)$ with $74 \%$ of respondents having a score above neutral.

When asked about their existing social network at the café, $58 \%$ reported having at least one acquaintance at the café, with an average of 4.2 acquaintances each. Only $25 \%$ reported having at least one personal friend at the café, averaging 2.8 each, and $20 \%$ reporting having emotionally $(M=2.6)$ or instrumentally $(M=2.4)$ supportive friends there. Our measures of psychological sense of community and place attachment showed that while people were fairly neutral in their sense of community $(M=3.5)$, they had a sense of attachment on the dependency $(M=5.4)$ and commitment dimensions $(M=5.3)$, but less so on the identity dimension $(M=3.4)$.

\section{Predicting Adoption of CoCollage}

We examined pair-wise correlations to explore which variables had a meaningful impact on adoption of CoCollage. Consistent with our predictions, a psychological sense of community, the identity dimension of place attachment, and a desire to connect to others in the café correlated with technology adoption. We found that the size of their existing social network in the café and their general friend-seeking level did not have a direct meaningful impact. See correlations in Table 1. We also found that the size of social network in the café, place-based sense of community and place attachment were strongly correlated. 
Correlations Among Size of Network, Sense of Community, and Place Attachment

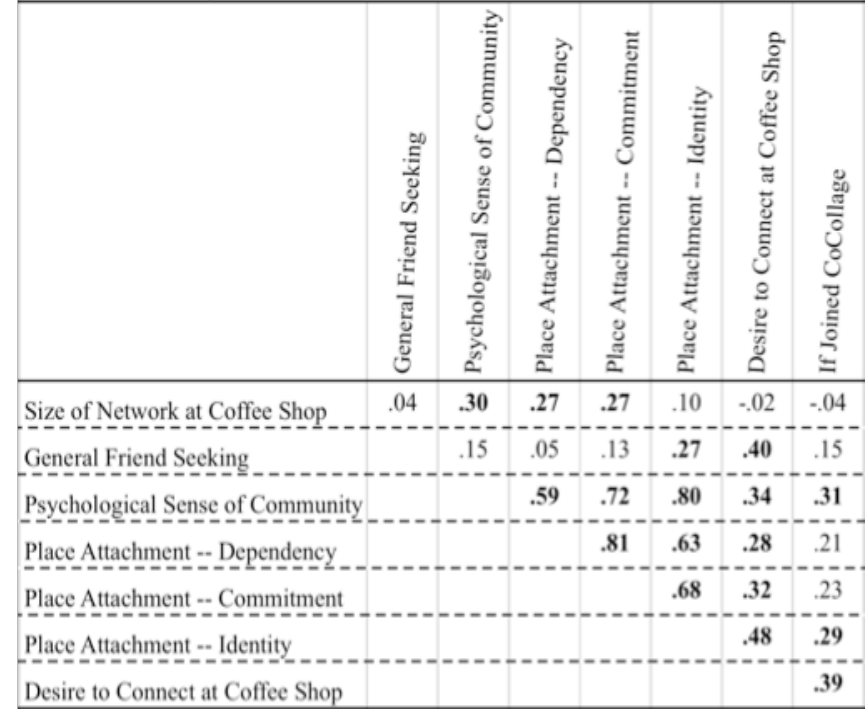

Table 1. Variables predicting if joined CoCollage. Bolded items are statistically significant at $p<.05$.

We entered these variables in a logistic regression to assess their relative impact. We found that both sex and age impacted the probability of signing up for CoCollage, such that males were marginally more likely to join, $\mathrm{c}^{2}(1, N=$ $54)=3.61, p<.06$, and younger people were more likely to join, $\mathrm{c}^{2}(1, N=54)=9.69, p<.002$. The size of existing network had no significant impact, desire for connection had a marginal impact, $\mathrm{c}^{2}(1, N=54)=5.66, \mathrm{p}<.06$, place attachment had a marginal impact, $\mathrm{c}^{2}(3, N=54)=7.42, p<$ .06 , and sense of community had a strong impact, $\mathrm{c}^{2}(1, N=$ 54) $=19.18, p<.001$.

\section{Initial Usage of the System}

Within the first month of our deployment 82 people voluntarily created accounts in the system, which represents about 20\% adoption among the "regulars". We examined some basic usage statistics to answer whether people are using the community features. The majority of users have uploaded content to share on the CoCollage display $(71 \%$, averaging 16 images each), browsed other people's profiles $(86 \%)$, and browsed other people's content $(57 \%, 40$ item views each). Shared images were largely photos of friends, pets, the local urban environment, traveling, and nature. About half of the pictures shared personally meaningful information about the author. Between $20 \%$ and $30 \%$ further added comments to images and profiles, and sent instant messages to the display screen. We found a significant correlation between the desire to make friends and the number of comments they post on others' profiles $(r$ $=.43, p<.05)$ and the number of unique days they have returned to the system $(r=.43, p<.05)$.

\section{CONCLUSION}

CoCollage was designed to provide increased opportunities for community awareness and interaction in third places through the large display and through online sharing and communication. Over the course of the first month of our deployment in a cafe, the user population has grown to about $40 \%$ of the target population. Our questionnaire results shows that people who a) are looking to connect with others, b) already have a sense of community at the café, and c) already feel place attachment to the café, are more likely to join CoCollage and start conversations.

Given the growing interest in the use of technologies to enhance social awareness and interactions in various physical places, we hope others may find our methods valuable in understanding the interplay between technology usage and the psycho-social factors of the third place. In future work, we hope to report our results on why and how CoCollage affects the awareness, interactions and relationships among members of the café community over time. We expect that continued use of the technology will increase people's sense of community and place attachment, and promote adoption by others.

\section{REFERENCES}

1.Blanchard, A.L. Developing a sense of virtual community measure. CyberPsychology and Behavior, 10:6 (2007), 827-830.

2.Churchill, E. F., Nelson, L. D. and Hsieh, G. Café life in the digital age: augmenting information flow in a caféwork-entertainment space. CHI 2006 Extended Abstracts. ACM Press, 123-128.

3.Greenberg, S., and M. Rounding. The notification collage: Posting information to public and personal displays. In Proc. CHI 2001, ACM Press, 515-521.

4.Kelly, S.U., Sung, C. and Farnham, S.D. Designing for improved social responsibility, user participation, and content in on-line communities. Proc. CHI 2002, ACM Press, 391-398.

5.McCarthy, J.F., Congleton, B. and Harper, F. M. The context, content \& community collage: Sharing personal digital media in the physical workplace. Proc. $C S C W$ 2008, ACM Press, 97-106.

6.Oldenburg, R. The Great Good Place: Cafés, Coffee Shops, Bookstores, Bars, Hair Salons, and Other Hangouts at the Heart of a Community. New York: Paragon Books (1989).

7.Rosenbaum, M.S., James, W., Walker, B.A., and Ostrom, A.L. A cup of coffee with a dash of love: An investigation of commercial social support and third-place attachment. J. of Service Research, 10:1, (2007) 43-59.

8.Terveen, L., and McDonald, D.W. Social matching: A framework and research agenda. ACM Trans. on Computer-Human Interaction, 12:3 (2005), 401-434.

9.Wilkinson, D. The multidimensional nature of social cohesion: Psychological sense of community, attraction and neighboring. Am. J. of Community Psychology, 40:34 (2007), 214-229. 